\title{
Trust: From Cognition to Conceptual Models and Design
}

\author{
Alistair Sutcliffe \\ School of Informatics, University of Manchester, \\ PO Box 88, Manchester, UK \\ ags@manchester.ac.uk
}

\begin{abstract}
Trust as a design issue for information systems has appeared in e-commerce, e-science, and a wide variety of collaborative applications. Much discussion has centred around trust in computational artefacts such as protocols, encryption and security mechanisms; however, little research has focused on exactly what trust means in human terms. In this presentation I will review the psychology literature on trust as a product of reasoning processes, and describe a cognitive model to explain and predict inter-personal and inter-organisational trust. I argue that sound design should be based on cognitive models of users, and these should inform the semantics of conceptual modelling as well as guiding the design process. I will explore the implications of the cognitive model of trust for conceptual modelling in requirements specification languages such as $i^{*}$. The final part will be more speculative. After a brief review of the implementations of trust-enhancing mechanisms in collaborative and e-science systems, focusing on user interface features rather than encryption, etc. middleware, I will discuss the design challenges for future trustworthy systems. This will cover how trust can be communicated, and issues of honesty when users may not always have the best intentions.
\end{abstract}

\section{Introduction}

Since trust has frequently been associated only with connotations of security and privacy (Haley, Laney et al., 2004; Giorgini, Massacci et al., 2005), the scope and interaction of trust-related issues in information systems development needs to be investigated. This leads to investigating how trust as a phenomenon can be interpreted in conceptual models and requirements specifications of systems. Modelling and designing for trustworthy or trust-promoting systems necessitates understanding and applying psychological and socio-psychological theories that explain trust and related phenomena. Trust has a social dimension in its role of governing personal relationships; it also has implications for how we make decisions, when we decide how to react to objects and people, as trustworthy or not. However, to realise the value in modelling trust, design implications should be discovered. To make some progress in this direction I will propose a framework for modelling trust-related issues, and then apply the framework in a case study of e-science. Trust has been highlighted as a social issue in the UK e-science programme; however, to date there has been little research that defines what trust means in e-science or how it should be interpreted in designing collaborative software. 
The paper is organised as follows; a brief review of cognitive and social psychological models of trust is followed by a description of the framework of trust-related issues. The subsequent section applies the framework to analysing trust-related problems in e-science. Finally, a research agenda for trust-motivated research in information systems is discussed.

\section{Cognitive and Social Models of Trust}

In sociology, trust models have considered economic viewpoints of trust between organisations as well as social attitudes governing trust towards institutions and between groups. In transaction cost theory (Williamson, 1993), trust is viewed as a consequence of inter-organisational relationships and the evolution of markets. The nature of the transaction and value of the goods influences trust between the purchasers and vendor and trust is regarded as a means of reducing transaction costs (e.g. legal fees) in contracts. Thoburn and Takashima (1993) argue that the existence of contracts should not inevitably be taken to mean that trust is absent, and note that in highly interdependent relationships contracts must be supplemented by other measures such as relationship building and the development of transparent accounting procedures between alliance partners. This includes the development of a no-blame culture to encourage truthful reporting and an open and honest dialogue (Tomkins, 2001).

Korczynski (2000) developed a model to illustrate the multiple types of trust that underlie relationships in economic activity, and pointed out that trust has a "political" as well as an economic aspect. For example, those who act out of social and ethical motives will be trusted more than opportunistic individuals. In associations where the participants have a long "time horizon" developed through personal associations and shared vision, there is less likelihood that incumbents will be narrowly rational in calculating trust. The "political" aspects of trust involve aspects such as legitimacy, reputation, status and knowledge.

Sociological studies of trust follow the perspective of society as a whole (Barber, 1983) or from individual perspectives of personal trust (Lewis \& Weigert, 1985; Luhmann, 1979; Shapiro, 1987; Zucker, 1986). The primary definition used in the sociological literature is that of Barber (1983, p. 165), who defines trust as two expectations: "[that] of technically competent performance and ... of fiduciary obligation and responsibility". Generally sociologists consider trust to be developed over time and influenced by personality traits, social experiences, or commonly shared norms and values (Fukuyama, 1995). Risk is implied in trust, but the risk is a calculated one, so individuals may choose not to trust if the risk is too great.

Drawing upon the literature of several disciplines, Hupcey et al. (2001) propose a three-component model that contains (i) antecedents: a need which cannot be met without help from another; prior knowledge and/or experience of the other, and assessment of risk; (ii) attributes composed of dependency upon another to meet the need, choice or willingness to take some risk; expectation that the trusted individual will behave in a certain way; focus upon the behaviour related to the need and testing the trustworthiness of the individual; (iii) boundaries when trust ceases to exist if there is a perception of no choice or the risks outweigh the benefits. 
In psychology the emphasis is upon interpersonal relationships as defined by Rotter (1971, p. 444): "an expectancy held by an individual or a group that the word, promise, verbal or written statement of another individual or group can be relied on". However, trusting an individual places the trustor at risk (Kramer, 1999), and therefore relies upon encountering consistent and benevolent behaviour in others (Larzelere \& Huston, 1980). Cannon, Doney and Mullen (1998) define trust as a willingness to rely on another party, and therefore to make oneself vulnerable to that party.

Formal socio-cognitive models of trust have been proposed (Castelfranchi \& Falcone, 1998) with equations that attempt to evaluate the various factors that influence trusting relationships, such as the degree of delegation between the two parties, the motivations, risks and goals shared by the parties to establish the need for a relationship, and properties which can be evaluated to establish their reputations. The role of the environment and experience also influence how trust may be assessed within groups, although no clear means of assessing the impact of experience is given. The socio-cognitive theory of trust (Falcone \& Castelfranchi, 2001a, 2001b) represents a considerable synthesis of the literature; however, the equations and premises contain many assumptions which are not based on empirical evidence. Furthermore, the predictions of the model have not been validated in case studies or experiments.

Studies of trust in technology have investigated how people assess the trustworthiness of websites and have proposed guidelines for trust enhancing design (Neilsen, Molich et al., 2000). Empirical studies in e-commerce environments reviewed by Grabner-Krauter and Kaluscha (2003), focus on assessment of trustworthiness of websites as well as the web as an institution. Guidelines for promoting trust are reported with questionnaire inventories for assessing reputation of trustees. Corritore, Kracher and Wiedenbeck (2003) propose a model of trust oriented to assessment of websites and interactive products, which assesses quality factors such as usability and credibility balanced against the risk of entering into transactions on the web. A more comprehensive model (Riegelsberger, Sasse \& McCarthy, 2003) analyses trusting relationships and trust-enforcing institutions and proposes mechanisms for promoting trust in communities, with design guidelines to facilitate evaluation of intrinsic trust of the reputation of the trustee, as well as feedback from experience. However, Riegelsberger et al. note that external manifestations of trust can be subject to mimicry by ill-intentioned agents, so trust relies on well regulated communities.

The concept of trust has been elaborated into credibility in studies of websites (Fogg, Marshall et al., 2001), where trust is an attribute assigned to websites based on the user's assessment of several factors such as usability, accuracy of information, brand and persuasive features. However, Fogg proposed no specific model of trust per se. A more elaborate model based on qualitative and quantitative research is the twoprocess model of trust in which first impressions, based on the interface look and feel, are distinguished from more detailed evaluations, based on the analysis of source credibility, personalisation and predictability (Briggs, Burford et al., 2002). The relationship between trust, personalisation and brand was further investigated in a largescale experiment which also addressed methodological issues concerning the extent to which planned and actual behaviours converge (Briggs, Burford \& De Angeli, 2004).

Although the diversity in trust theories and models can be daunting, a common set of components appears in several theories. First there must be some motivation for 
one party to trust another. The fact that one party has a need which can potentially be met by the other implies a degree of vulnerability. This is because the trustor is placing themselves at some risk vis-à-vis the potentially more powerful party. A trustor has to feel some confidence in the past performance and reliability of the trusted party to assess whether they are likely to fulfil their part of the bargain. The trustor relies on the trusted, or trustee, to share their commitment towards achieving a goal. The boundaries of trust are reached when one party perceives that the risks in trusting the other party outweigh the potential benefits.

\section{Modelling Trust}

At the social level, trust is a relationship between the trustor and the trustee. There is an implicit asymmetry in the relationship between the latter, who is more powerful, and the trustor who is in some way more dependent on the trustee. Trust is associated with power (i.e. authority and perceived power), vulnerability and risk. Indeed trust can be seen as a type of insurance policy for making relationships manageable when there is some doubt about the intentions of the other party. If one individual perceives some risk or vulnerability which could be exploited in the relationship, the courses of action are either to abandon the relationship, or to adopt risk reduction via legal contracts, financial insurance, etc., or to trust the other party and hope for the best. Trust has the added advantage of being cheap; if it works it reduces the overhead of relationship management and promotes a better modus operandi.

In information systems, trust may be modelled as a relationship between individual agents, or organisations, as illustrated figure 1.

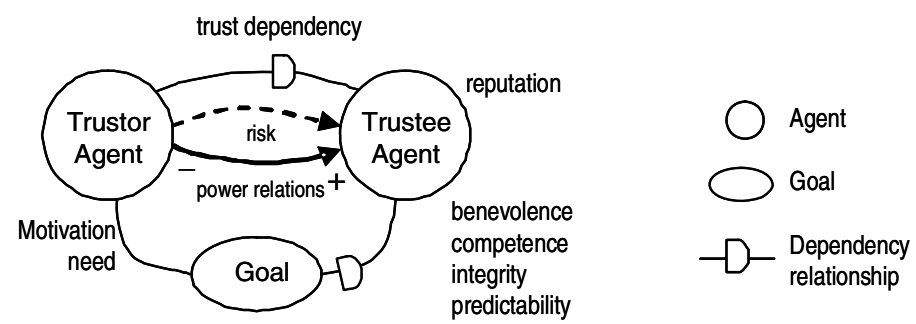

Fig. 1. Trust modelling conventions illustrated in an adaptation of $i *$ notation

Trust relationships are associated with a goal dependency in which the trustor relies on the trustee. The trustees' suitability depends on their competence to fulfil the goal, their benevolence not to exploit the trustor's vulnerability, their ethical integrity and predictability of their behaviour. The semantics of power relationships are worth modelling explicitly, since power asymmetry is invariably associated with trust; an evaluation function is required to assess the agent's reputation from its properties. The properties will vary between applications, individual agents and organisations; however, some generic properties which give an indication of domain specifics are honesty, history of trustworthiness, association with reliable agents, openness in negotiation, and membership of trustworthy organisations. Reputation assessment is 
accompanied by power asymmetry or vulnerability analysis; hence the overall assessment depends on each agent's need for trust, which is a combination of their goals and motivation for entering into the relationship, and vulnerability or risk exposure. The need for trust defines the requirements for the relationship, i.e. a highly asymmetric relationship implies a need for a higher level of trust than does a more symmetric relationship. Trust develops over time, so in the initial stages the trustee's reputation is evaluated either in depth or more superficially depending on the trustor's predisposition and the availability of information. As the relationship matures trust becomes a default assumption unless unpleasant experience triggers a review of the relationship.

\section{Cognitive Model of Trust}

Cognitive models place trust as in the context of theories of decision making, such as the theory of reasoned action (Klein, 1989) which asserts that decisions are influenced by a combination of the events and situation at a point in time combined with the user's prior memory and attitude towards the decision problem. Trust is a specialisation of such models in which the decision is to enter into a relationship with an agent depending on the situation and prior knowledge. The following cognitive model of trust considers both the reputation and experience components of trust. A four-stage process is proposed elaborating concepts in earlier phase models (Briggs et al., 2004) as illustrated in figure 2 .

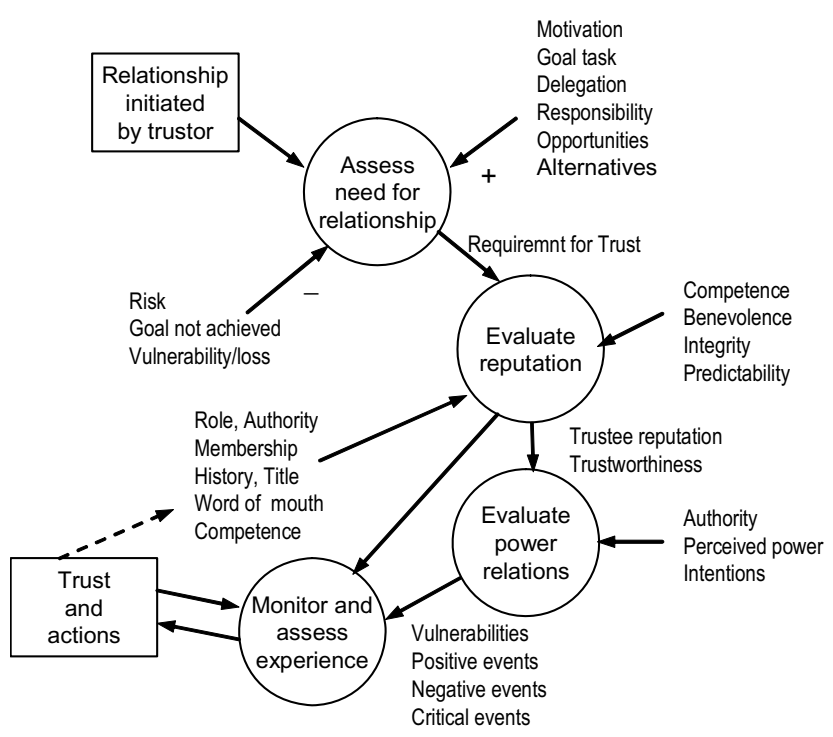

Fig. 2. Process model of trust-related decision making

The first stage is assessment of the need for trust. The trustor agent has a goal which requires the cooperation of another to achieve it. The importance of the goal is evaluated in light of the options available and the potential loss if the goal is not 
achieved. This assessment may be complex, involving trade-offs of recruiting multiple relationships, the degree of explicitness in the relationship (i.e. overt delegation or not), and alternatives to trust such as legal contracts, economic incentives, etc. While assessment details will be domain and situation specific, the essence is a motivation and risk calculation, expressed in equation 1. It creates a "need for trust" metric (Nt) as a function of need, motivation and potential loss.

$$
\mathrm{Nt}=(\mathrm{M}+\mathrm{G}+\mathrm{env}+(\mathrm{r} \cdot \mathrm{p}))
$$

Where

$\mathrm{M}=\quad$ motivation for entering the relationship

$\mathrm{G}=$ goal that one party wishes to achieve expressed as importance ranking

env $=$ environment factor that represents the degrees of freedom available to the trustor

$\mathrm{r}=\quad$ risk exposure

$\mathrm{p}=\quad$ perceived power difference between the parties.

Risk exposure and degree of choice available increase the need for trust value if the risk is high and there are few alternatives. Env is assessed as higher if fewer choices exist. As the risk and power asymmetry increases, the need for trust increases. The formula can be converted into a metric by estimating M, G, env and $\mathrm{r}$ on a 10-point (low to high) scale, with p expressed on a 0 to 1 scale where equal power $=0.5$ and $1.0=$ complete asymmetry in favour of the trustee. A constant of 0.5 modulates the effect of power on risk exposure. So with a high motivation and an important goal for the trustor, but with considerable risk and few options, the need for trust might be:

$$
\begin{gathered}
\mathrm{Nt}=(\mathrm{M}+\mathrm{G}+\mathrm{env}+\mathrm{r} \cdot(0.5+\mathrm{p})) \\
28.1=6+7+6+7 .(0.5+0.8)
\end{gathered}
$$

These metrics can be used for comparative evaluation of different need for trust situations; however, the trust values produced have no intrinsic validity. Motivation is the agent's predisposition to be trusting, while the goal represents the specific need. Risk is modulated by power to reflect the vulnerability of the trustor, i.e. a more powerful trustee will have increased ability to inflict loss on the trustor without repercussions.

In the second stage the opportunity to enter into a trusting relationships is evaluated in light of the need. This may involve a choice among several suitors so the risk exposure will need to be evaluated for each suitor agent. Reputations of each trustor are assessed from their perceived benevolence, competence, integrity and predictability. Assessment criteria will vary by domain and the availability of evidence for the trustor. However, typical reputation properties are the trustee's competence to achieve the goal, honesty, past trustworthiness, reputation as vouched for by others, membership of trusted organisations, and socio-demographic factors such as occupation, age, and gender. Reputations of the trustees are compared with the trustor's requirements for entering into the relationship. Equation 2 creates an "initial trust" metric as a function of needs and risk, balanced against the reputation of the trustee.

$$
\mathrm{T}^{\mathrm{i}}=\mathrm{R}-\mathrm{N}^{\mathrm{t}}
$$

Where

$\mathrm{T}^{\mathrm{i}}=$ Initial trustworthiness level

$\mathrm{R}=$ Reputation of the trustee

$\mathrm{N}^{\mathrm{t}}=$ trustor's need level from equation (1). 
The formula can be converted into a metric by estimating reputation on 40 point scale to balance with the need for trust. If the trustee's reputation is high and the trustor's need for trust does not exceed it, the starting level of trust will be positive. Alternatively, if the trustee has a poor reputation or it is exceeded by a high need for trust, then the starting trust level will be negative reflecting low confidence and mistrust. The value can be calculated in both directions in a relationship, although for asymmetric relationships the trustee is the focus of attention. A confidence metric may also be calculated based on the knowledge available to the trustor, risk exposure, and previous reputation history of the trustee. The level of confidence is fed into the threshold which determines when trust will switch into distrust.

Trusting relationships may change over time, so assessment of reputation only models the initial starting point between the two parties. Events influence the evolution of trust. Adverse events may be tolerated for a while but sooner or later, trust will rapidly decline into mistrust, from which there is no quick escape, as demonstrated by empirical studies on the effect of errors on trust in computer applications (Lee \& Moray, 1992). Once this initial trust value has been established, the experience component of the model predicts change over time, as described in equation 3 :

$$
\mathrm{T}^{\mathrm{i}}=\mathrm{T}^{\mathrm{i}-1} \mathrm{f}^{\mathrm{th}}(\mathrm{E} \cdot \mathrm{w})
$$

Where

$\mathrm{T}^{\mathrm{i},}=$ level of trust in time interval $\mathrm{i}$ and the previous interval $\mathrm{i}-1$

$\mathrm{E}=$ experiences which may be either positive, confirming or increasing trust; or negative and leading to suspicion about trustworthiness of the trustee

$\mathrm{w}=$ weighting factor for the criticality of each event

$\mathrm{f}=$ function determining trust increase or decrease

th $=$ threshold that influences the trend function of the initial reputationbased trust.

The threshold function controls the four separate trend patterns according to the initial reputation and history of the experience:

1. an initial high level of trust survives several adverse experiences but if the negative events continue once a critical threshold is exceeded trust will rapidly decrease into distrust

2. a low level of initial trust will experience gradual improvement with positive experience and a similar decrease in trust with adverse experience

3. a relationship that started with high trust and descended into mistrust has a very poor recovery function, so a large number of positive events are required before trust is regained

4. mid-range trust values have an increasing gradient with positive experience and a rapid decrease with adverse experience.

A screen dump of the computational tool that embeds the theory is illustrated in figure 3 .

The model is controlled by parameters and thresholds which determine when the functions change for ascending or descending trust, as well as allowing the model to be tailored for a specific domain, e.g. the number and strength of positive and negative 


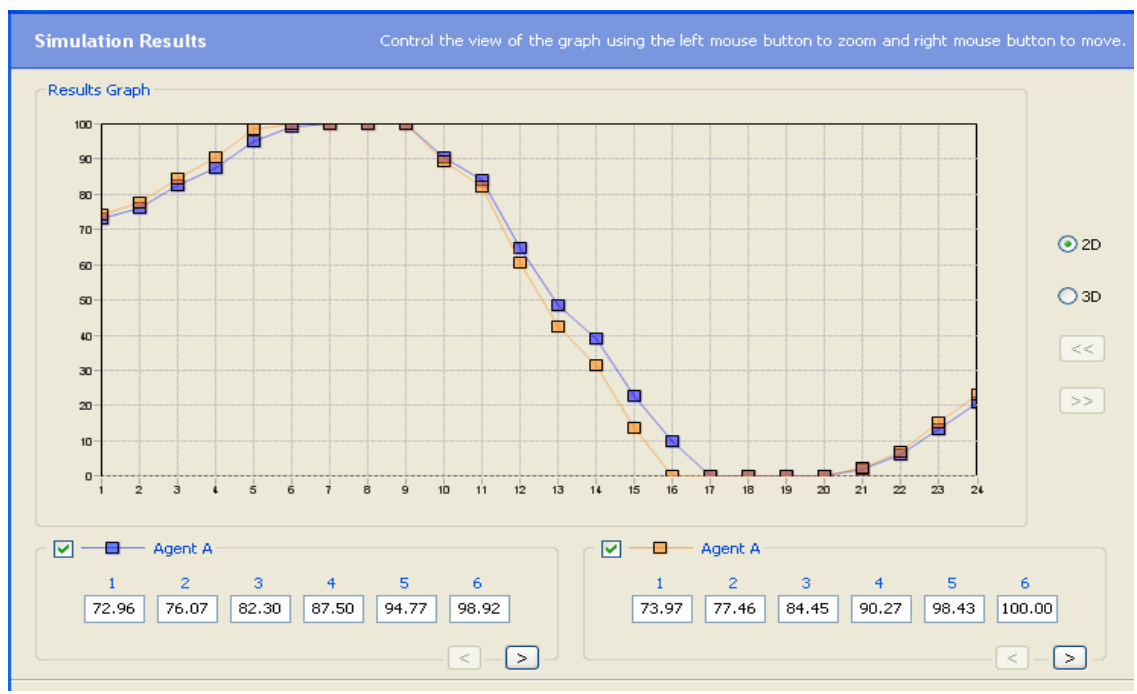

Fig. 3. Screen dump of tool that models Dynamic Trust Theory, showing a simulated time course of a relationship (pattern 1 followed by 3 )

events that will precipitate rapid descent to mistrust, etc. Event criticality is reflected in the weighting factor as well as the input value assigned to each event. Assessment of experience also depends on domain-specific interpretation of the number and valency of events necessary and how the significance of events is determined. Typical events in inter-organisational relationships are meeting deadlines, compliance with commitments, provision of information, prompt responses, willingness to help the other party, etc. Failure to fulfil obligations without any reason, and deceit in covering up failure, are typical critical negative experiences. The agent's reputation parameters are entered as the settings for variables 1 to 6 and the plot shows the change in trust with an experience scenario that starts with positive events followed by critical negative events leading to rapid decline in trust.

\section{Framework for Trust Modelling}

So far, the model has assumed agents (individual or organisational) were involved as both parties; however, we also trust artefacts, products, information, processes, and data. The relationship motivation and vulnerability analysis still apply. The risk exposure of using the object is assessed to determine the need for trust. The object's reputation can be assessed as before; furthermore, for products the attribute of brand is an important component of trust, as it is for inter-organisational relationships. The problem space of trust issues and relationships is summarised in figure 4.

The nature of experience with trusted objects depends on whether they are active or passive. Active objects, for example mobile phones, exhibit behaviour resulting in the user's experience, which may be favourable or not. Any device which causes frequent 


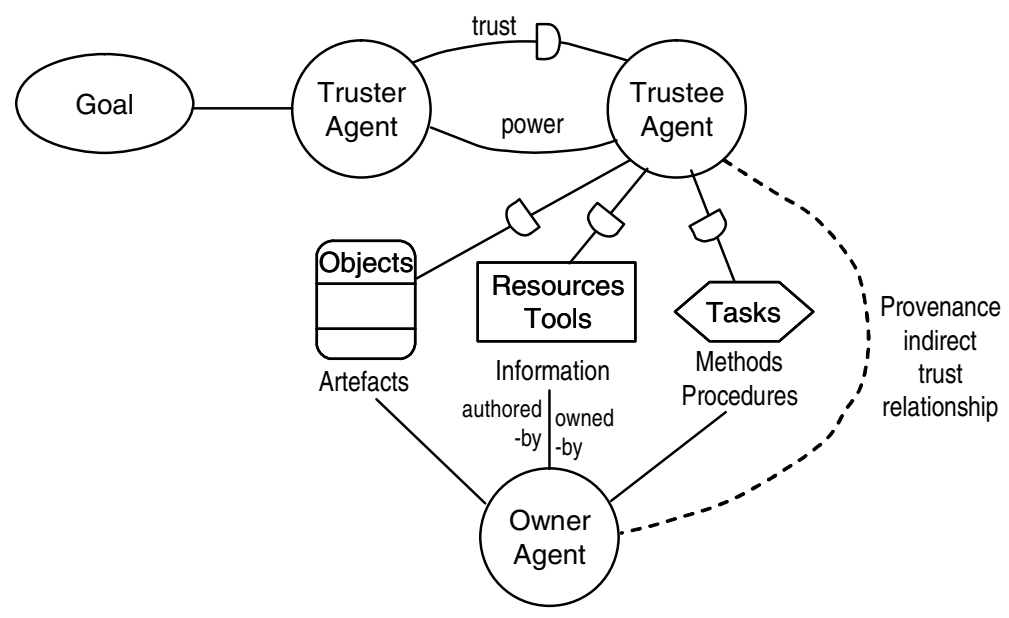

Fig. 4. Framework of trust issues and relationships

errors will rapidly become distrusted. A passive object such as a book has no inherent behaviour but can be experienced through reading. Trust in an author's work may develop if the reader feels the plots are consistently well constructed. Finally, some passive objects may not be directly experienced in use; for instance, a painting is appreciated aesthetically but not actually used. Trust in this case depends on the quality of the perceptual experience. Hence trust is closely related to use and possibly aesthetics. In HCI there has been considerable interest in assessing qualities of use including usability, aesthetics and the user's experience (Hassenzahl, 2004; Lavie \& Tractinsky, 2004; Sutcliffe \& De Angeli, 2005). However, these measures have not been correlated with the development of trust between users and a software product, although some authors have argued that the quality of experience and aesthetic appeal are critical determinants of a product's success because the experience creates a positive emotional response (i.e. pleasure) and this fosters trust (McCarthy \& Wright, 2005; Norman 2004).

\subsection{Design Implications}

Modelling trust may illuminate our understanding of a socio-technical system; however, without any design implications its utility will be limited. Design and trust intersect in two ways. First, software products need to be designed so users trust them and have a positive experience. Secondly, technology is a mediator of trust between people, organisations or products. The first role is fulfilled by good design, e.g. usability, appropriate functionality, professional aesthetic look and feel, as well as design to facilitate trust through ownership via customisation and adaptation to the user's needs. In the second role, technology should reduce the uncertainty in relationships and thereby increase trust by making information more accessible, and by communicating status, identity, intent and processes transparently. Better quality functions can help evaluating reputations to promote trust, e.g. display of status information, memberships and authorisations, recommender systems, and evaluation of reputation 
berships and authorisations, recommender systems, and evaluation of reputation by social feedback. Feedback also supports the experience phase of the relationship allowing people to inspect the action of the trustee. Technology has a role to play in policing trust, by providing support for institutions and communities to ensure human members act by the rules with pattern recognisers to detect deceitful behaviour, identity checks and community feedback on the trustworthiness of individuals.

Several sets of guidelines have been proposed for trust enhancement, primarily in e-commerce (Nielsen, 2000), and some advice has been offered on trust support for general computer supported collaborative work (Olson \& Olson, 2000). Rather than reiterate the guidelines in detail the following heuristics are proposed to guide the designer towards the issues that should be considered:

- Competence factors: trust is increased if the trustee agent achieves the user's (trustor's) goal effectively. This emphasises the tailoring of functional requirements towards stakeholder groups or specific individuals. Competence also involves good navigation design and usability, so the user's experience is positive. Poor usability has a negative impact on trust.

- Benevolence: this property reflects more directly on the developer or owner of the application. Favourable predispositions can be communicated by statements of honesty, access to the people who operate the application, and provision of information about the developers/owners. In e-commerce applications this is reflected in guidelines for "contact us" and "about us" information, and statements of fair trading policies, etc.

- Integrity: this reflects the ethical standards of the developers/owners and can be conveyed by brand images, membership of trustworthy organisations, compliance with standards, and certification authorities.

- Predictability: this is a consistent experience related to good usability, reliable applications, and prevention of errors.

Trust is also enhanced by good design for related non-functional requirements such as accuracy (of information), privacy, security and reliability. Usability reduces uncertainty by making interaction predictable with clear feedback, hence building confidence in an application.

Design for trust may also involve fostering relationships between human and organisational parties more directly by processes to facilitate matching of trustors and trustees, and vetting services for reputation management. Recommender systems, brokers, and social feedback facilities such as eBay's vendor reputation management are examples of functions for trust relationship management. Workflow, version control, and coordination tools help build trust by efficient relationship management. Logging and monitoring tools can track experience and make processes transparent by shared data and models, while status displays can help build confidence in relationships, thereby building trust. Provision of more information about individuals and the ability to query claims and identities reduce the opportunities for deceit. In the next section the framework and process model of trust is applied to an e-science domain to investigate how design for trust might be deployed. 


\section{Case Study: Modelling Trust in e-Science}

E-science is the collaboration between remote groups of scientists mediated by CSCW (Computer Supported Collaborative Work) technology and GRID computing over the Internet. Although e-science is proposed as an empowering form of reorganising work practice, evidence of successful e-science collaboration is hard to find, and furthermore, the few evaluations that have been carried out (Cummings \& Kiesler, in press) point to several reasons why collaborations have been unsuccessful. Although several causal factors were cited such as clash of time zones, organisational cultures, and inadequate technology, the lack of trust between teams was a contributing factor.

\subsection{Applying the Framework}

Trust in relationships between individuals and between teams is an important aspect of improving relationships. Socio-psychological theories of group working (Arrow, McGrath \& Berdahl, 2000) emphasise the importance of frequent social contacts that build a network of relationships between group members and hence create trust. The role of CSCW and GRID video conference technology in promoting good social bonds is poor, hence there may be no substitute for face-to-face interaction to build this aspect of trust. However, the reputation of individuals and groups can be assessed and this might provide an indicator of the trust requirements, when considered with the needs of each group to enter into a collaboration.

The following example is based on e-science collaboration in genomic research in which teams of biomedical researchers are trying to understand the complicated process by which genes (DNA) are transcribed into an intermediate form (RNA) which is then used to produce proteins in cells by complicated bio-chemical processes. Unfortunately the mapping of genes (segments of DNA) to protein (sequences of amino acids) is not 1 to 1 . A common approach is to segment chromosomes into gene fragments, provide the in vivo environment for protein synthesis using the gene (DNA sequence) fragments, assay the proteins produced, then try the experiment with different inhibitor chemicals and DNA segments to see when the inhibitors stop production of the protein, thus confirming that DNA segment $x$ is responsible for producing protein $y$. This process is time consuming and could benefit from a combined approach where teams try different inhibitors on the same sequence, etc. The model of the collaboration, illustrated in figure 5 , is produced by applying the trust analysis method as follows:

Motivation Analysis: the motivation for the relationship is not strong since each team can continue to work incrementally as before. However, the risk exposure of collaboration is relatively low since each team will still have results to publish, although there is the possible loss of not being the team to make the scientific breakthrough. This creates a moderate need for trust.

Reputation Analysis: the reputation of each group depends on their host universities and publication record; in this case reputation was approximately equal and both teams were relatively well funded so the power balance is almost symmetrical. Reputation is reinforced by the need for trust, so e-science technology has to lower the cost of 
collaboration and foster trust. The teams trust the artefacts produced by their experimental processes, e.g. microarrays, chromatography gels; the procedures they follow which are set by conventions and the refereeing process in the biomedical research community; and the analytic instruments they use (DNA and protein sequence auto-analysers) which involves trusting the manufacturers. The trust relationships are all interdependent. The teams trust their own results and artefacts, but that depends on following procedures accurately and tools performing correctly. For each team to trust the other they not only have to assess their mutual interests and respective reputations, but also the second order trust relationships with procedures, etc. in each group.

Experience Analysis: in e-science CSCW technology can promote trust and manage experience by making the experimental artefacts and procedures shareable. This allows each team to inspect each other's progress, working methods and results to build confidence in the collaboration. However, as noted in the motivation analysis, such sharing does involve some risk, so security and privacy have to be guaranteed, and visibly so. Frequent communication via video conferencing can help to build trust by facilitating social interaction. However, there are limitations in the ability of collaborative technology to promote trust. The benevolence of each team, their competence and integrity are human properties that can be communicated but not enhanced by technology.

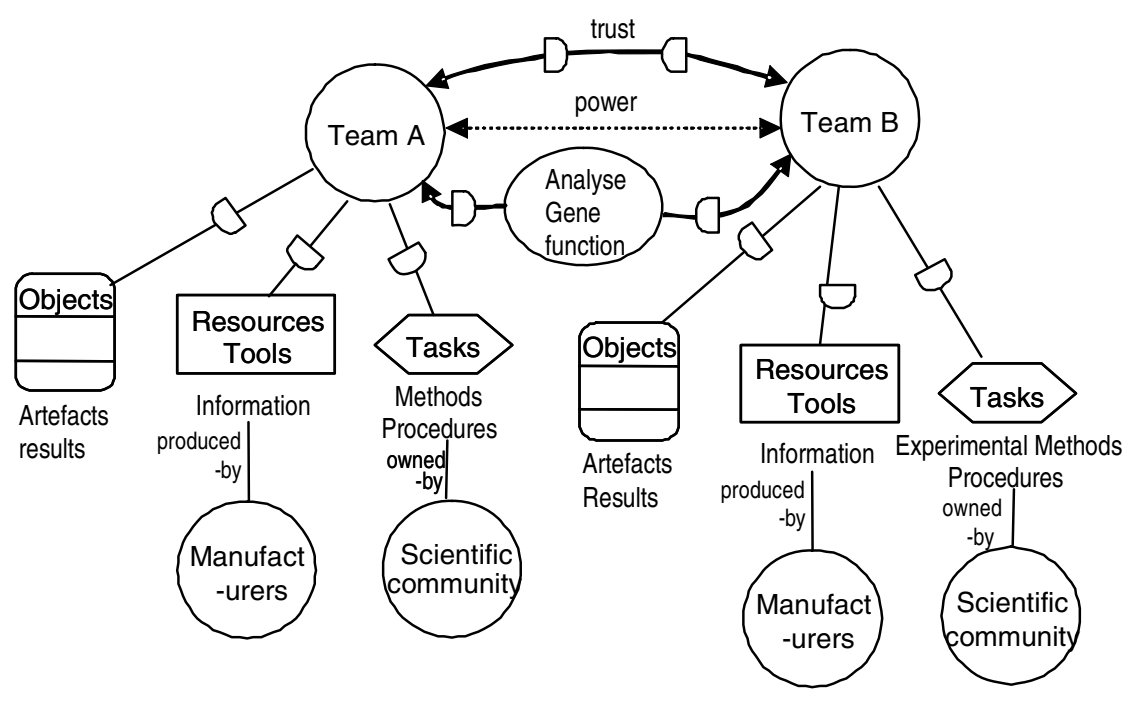

Fig. 5. Model of e-science collaboration

Promoting trust in e-science has to overcome the problem of low motivation or adopting the technology by lowering the cost of establishing trust. This can be achieved by enhancing the shareability and visibility of the methods, procedures and results between teams to build confidence. Increasing the visibility of each team's experimental procedures helps build confidence in the competence and integrity of each team, and may have the side benefit of facilitating sharing of workflows for experimental procedures. Since social interaction is an important influence for build- 
ing trust between groups (Arrow et al., 2000), use of video conference facilities as well as e-mail can enhance relationship building. Since e-science collaborations are agreements in communities with little formal regulation, technology does not have a trust policing role. Trust in e-science tools and collaborative technology is also a function of usability in design (predictability in interaction), as well as fulfilling users' requirements (competence).

\section{Conclusions}

Trust is a complicated topic which is difficult to pin down, since it can be viewed from many perspectives. A plethora of models have been proposed, unfortunately exceeding the volume of empirical evidence to justify their assumptions. The model proposed in this paper takes a process perspective to draw attention to how trust can be evaluated, as well as pointing out the components of trust synthesised from other theories.

As systems move into the social domain on the Internet and Cyber communities, where use become discretionary, understanding and designing for trust-promoting facilities will be a growing concern. Further research is necessary to improve the link between trust and uncertainty by better provision of information, and to understand how trust in applications can be promoted by good design (competence). A more significant challenge lies in developing trust management systems. The easy design options of certificates for membership and identity, logging behaviours and social feedback have already been implemented. However, the role of active agents, recommender systems and brokers still needs to be explored in depth. The penalty here lies in bad experience when intelligent systems make poor guesses, leading users to distrust them.

Trust modelling is still in its infancy. Although some modelling languages such as $i^{*}$ have been used to analyse trust and more formal models have been proposed, these do not address the complexities of trust in socio-technical systems. Modelling methods and tools are required to better understand how risk, trust and power interact. There are considerable opportunities for tool development to evaluate trust; however, given that evaluation details will frequently be domain dependent, such tools will need to be configurable.

Finally, trust is but one facet of the complexity of human social relationships that needs to be approached within a wider, theoretically sound framework. Theories of decision making (Klein, 1996; Payne, Bettman \& Johnson, 1993) or socio-psychological models of group behaviour (Arrow et al., 2000) may provide the answer. Integrating such theories into conceptual modelling languages is the grand challenge for information systems engineering, and trust may well provide the stimulus.

\section{References}

Arrow, H., McGrath, J. E., \& Berdahl, J. L. (2000). Small groups as complex systems: Formation, coordination, development and adaptation. Thousand Oaks CA: Sage Publications.

Barber, B. (1983). The logic and limits of trust. New Brunswick NJ: Rutgers University Press.

Briggs, P., Burford, B., \& De Angeli, A. (2004). Personalisation and trust: A reciprocal relationship? In K. Karat, J. O. Blom, \& J. Karat (Eds.), Designing personalised user experiences in e-commerce (pp. 39-55). Norwell MA: Kluwer Academic Publishers. 
Briggs, P., Burford, B., De Angeli, A., \& Lynch, P. (2002). Trust in online advice. Social Science Computer Review, 20(3), 321-332.

Cannon, J., Doney, P., \& Mullen, M. (1998). National culture and the development of trust: The need for more data and more theory. Academy of Management Review, 24(1), 8-11.

Castelfranchi, C., \& Falcone, R. (1998). Social trust: Cognitive anatomy, social importance, quantification and dynamics. Proceedings: Autonomous Agents '98 Workshop on Deception, Fraud and Trust in Agent Societies, Minneapolis/St Paul, (pp. 35-49).

Corritore, C. L., Kracher, B., \& Wiedenbeck, S. (2003). On-line trust: Concepts, evolving themes, a model. International Journal of Human-Computer Studies, 58, 737-758.

Cummings, J., \& Kiesler, S. (in press). Collaborative research across disciplinary and organizational boundaries. Social Studies of Science.

Falcone, R., \& Castelfranchi, C. (2001a). Social trust: A cognitive approach. In C. Castelfranchi, \& Y. Tan (Eds.), Trust and deception in virtual societies (pp. 55-90). Boston MA: Kluwer Academic Publishers.

Falcone, R., \& Castelfranchi, C. (2001b). The socio-cognitive dynamics of trust: Does trust create trust? In R. Falcone, M. Singh, \& Y. Tan (Eds.), Trust in cybersocieties: Integrating the human and artificial perspectives (pp. 55-72). Berlin: Springer.

Fogg, B. J., Marshall, J., Laraki, O., Osipovish, A., Varma, C., et al. (2001). What makes web sites credible? A report on a large quantitative study. In J. A. Jacko, A. Sears, M. BeaudouinLafon, \& R. J. K. Jacob, (Eds). CHI 2001 Conference Proceedings: Conference on Human Factors in Computing Systems, Seattle 31 March-5 April 2001. New York: ACM Press.

Fukuyama, F. (1995). Trust: The social virtues and the creation of prosperity. New York: Free Press.

Giorgini, P., Massacci, F., Mylopoulos, J., \& Zannone, N. (2005). Modeling security requirements through ownership, permission, and delegation. Proceedings: 13th IEEE International Conference on Requirements Engineering, Paris 29 August - 2 September 2005, (pp. 167-176). Los Alamitos CA: IEEE Computer Society Press.

Grabner-Krauter, S., \& Kaluscha, E. A. (2003). Empirical research in online-trust: A review and critical assessment. International Journal of Human-Computer Studies, 58, 783-821.

Haley, C. B., Laney, R., Moffett, J. D., \& Nuseibeh, B. (2004). The effect of trust assumptions on the elaboration of security requirements. Proceedings: 12th IEEE International Conference on Requirements Engineering, Kyoto 6-10 September 2004,. Los Alamitos CA: IEEE Computer Society Press.

Hassenzahl, M. (2004). The interplay of beauty, goodness and usability in interactive products. Human-Computer Interaction, 19(4), 319-349.

Hupcey, J. E., \& et al. (2001). An exploration and advancement of the concept of trust. Journal of Advanced Nursing, 36(2), 282-293.

Klein, G. A. (1989). Recognition-primed decisions. In W. B. Rouse (Ed.), Advances in manmachine systems research (Vol. 5) (pp. 47-92). Greenwich CT: JAI Press.

Klein, S. (1996). The configuration of inter-organisational relations. European Journal of Information Systems, 5, 92-102.

Korczynski, M. (2000). The political economy of trust. Journal of Management Studies, 37(1), $1-22$.

Kramer, R. M. (1999). Trust and distrust in organizations: Emerging perspectives, enduring questions. Annual Review of Psychology, 50, 556-557.

Larzelere, R. J., \& Huston, T. L. (1980). The dyadic trust scale: Toward understanding interpersonal trust in close relationships. Journal of Marriage and the Family, 42(August), 595-604.

Lavie, T., \& Tractinsky, N. (2004). Assessing dimensions of perceived visual aesthetics of web sites. International Journal of Human-Computer Studies, 60(3), 269-298.

Lee, J., \& Moray, N. (1992). Trust, control strategies and allocation of function in human machine systems. Ergonomics, 35(1), 1243-1270.

Lewis, J., \& Weigert, A. (1985). Trust as a social reality. Social Forces, 63, 967-985. 
Luhmann, N. (1979). Trust and power. New York: Wiley.

McCarthy, J., \& Wright, P. (2005). Technology as experience. Cambridge MA: MIT Press.

Nielsen, J. (2000). Designing web usability: The practice of simplicity. New Riders.

Nielsen, J., Molich, R., Snyder, S., \& Farell, C. (2000). E-commerce user experience: Trust. Nielsen Norman Group.

Norman, D. A. (2004). Emotional design: Why we love (or hate) everyday things. New York: Basic Books.

Olson, G. M., \& Olson J.S. (2000). Distance matters. Human-Computer Interaction, 15(2), 139-178.

Payne, J. W., Bettman, J. R., \& Johnson, E. J. (1993). The adaptive decision maker. Cambridge: Cambridge University Press.

Riegelsberger, J., Sasse, M. A., \& McCarthy, J. D. (2003). Shiny happy people building trust? Photos on e-commerce websites and consumer trust. In V. Bellotti, T. Erickson, G. Cockton, \& P. Korhonen, (Eds). CHI 2003 Conference Proceedings: Conference on Human Factors in Computing Systems, Fort Lauderdale FL 5-10 April 2003, (pp. 121-128). New York: ACM Press.

Rotter, J. B. (1971). Generalised expectancies for interpersonal trust. American Psychologist, 26, 443-452.

Shapiro, S. (1987). The social control of interpersonal trust. American Journal of Sociology, 93, 623-658.

Sutcliffe, A. G., \& De Angeli, A. (2005). Assessing interaction styles in web user interfaces. In M. F. Costabile, \& F. Paterno, (Eds). Proceedings: Human Computer Interaction - Interact 2005, Rome, (pp. 405-417). Berlin: Springer Verlag.

Thoburn, J. T., \& Takashima, M. (1993). Industrial performance: Lessons from Japanese subcontracting. National Westminster Bank Quarterly Review (February), 2-11.

Tomkins, C. (2001). Interdependencies, trust and information in relationships, alliances and networks. Accounting, Organizations and Society, 26(2), 161-191.

Williamson, O. E. (1993). Calculativeness, trust and economic organization. Journal of Law and Economics, 36, 453-486.

Zucker, L. G. (1986). The production of trust: Institutional sources of economic structure, 1840-1920. In B. M. Staw, \& L. L. Cummings (Eds.), Research in Organizational Behaviour (pp. 8:55-111). Greenwich CT: JAI Press. 